\title{
Long Latency Auditory Evoked Potential in Term and Premature Infants
}

\author{
Dayane Domeneghini Didoné ${ }^{1} \quad$ Michele Vargas Garcia ${ }^{1} \quad$ Aron Ferreira da Silveira ${ }^{2}$
}

1 Fonoaudiology, Universidade Federal de Santa Maria, Santa Maria, RS, Brazil

${ }^{2}$ Department of Morphology, Universidade Federal de Santa Maria, Santa Maria, RS, Brazil

Address for correspondence Dayane Domeneghini Didoné, Mestre em Distúrbios da Comunicação Humana pela, Fonoaudiologia, Universidade Federal de Santa Maria, Rua João Goulart, Bairro: Camobi, Santa Maria, RS 97105-220, Brazil (e-mail: dayanedidone@yahoo.com.br).

Int Arch Otorhinolaryngol 2014;18:16-20.

\begin{abstract}
Introduction The research in long latency auditory evokes potentials (LLAEP) in newborns is recent because of the cortical structure maturation, but studies note that these potentials may be evidenced at this age and could be considered as indicators of cognitive development.

Purpose To research the exogenous potentials in term and premature infants during their first month of life.

Materials and Methods The sample consisted of 25 newborns, 15 term and 10 premature infants. The infants with gestational age under 37 weeks were considered premature. To evaluate the cortical potentials, the infants remained in natural sleep. The LLAEPs were researched binaurally, through insertion earphones, with frequent / ba/ and rare $/ \mathrm{ga} /$ speech stimuli in the intensity of $80 \mathrm{~dB} \mathrm{HL}$ (decibel hearing level). The frequent stimuli presented a total of $80 \%$ of the presentations, and the rare, $20 \%$. The data were statistically analyzed.

Results The average gestational age of the term infants was 38.9 weeks $( \pm 1.3)$ and for the premature group, 33.9 weeks $( \pm 1.6)$. It was possible to observe only the

\section{Keywords}

- evoked potentials auditory

- prematurity

- newborn potentials $\mathrm{P} 1$ and $\mathrm{N} 1$ in both groups, but there was no statistically significant difference for the latencies of the components P1 and N1 $(p>0.05)$ between the groups.

Conclusion It was possible to observe the exogenous components $\mathrm{P} 1$ and $\mathrm{N} 1$ of the cortical potentials in both term and preterm newborns of no more than 1 month of age. However, there was no difference between the groups.
\end{abstract}

\section{Introduction}

Hearing electrophysiology is related to objective examinations. These examinations can measure the auditory electrophysiologic hearing thresholds and can be used in newborn and older infants who do not cooperate in behavioral evaluations. The most often applied electrophysiologic examinations in newborns are the brainstem auditory evoked potential (BAEP) and the auditory steady state responses (ASSR), which aim at determining the electrophysiologic hearing thresholds.
The auditory hearing thresholds are significant during linguistic development, but also the integrity and proper characteristics of the central structures should be observed. Thus, some authors have used the auditory evoked long latency potentials to evaluate the auditory processing.

Cortical potentials allow objective assessment of cognitive abilities of attention, memory, and discrimination of sounds. ${ }^{1}$ Therefore, ascertaining the integrity and functionality of the central structures complements the diagnosis of auditory processing disorders. received

August 21, 2013

accepted after revision

September 4, 2013
DOI http://dx.doi.org/ 10.1055/s-0033-1358658. ISSN 1809-9777.
Copyright $(2014$ by Thieme Publicações License terms Ltda, Rio de Janeiro, Brazil

(®) $\ominus \circledast$ 
The research about auditory evoked long latency potentials in newborns is a recent and controversial subject, because of the maturation of the cortical structures. However, some studies have already noted that these potentials may be evidenced during childhood. They are considered as measurers of cognitive development, mainly in preterm infants, who present risks for auditory processing disorders. ${ }^{2-4}$ Some studies verified that children with altered cortical potentials during the neonatal period could present linguistic alterations. $^{5}$

The auditory evoked long latency potentials reflect the electrical activity from the peripheral auditory system to the central auditory pathway. They aim at verifying the auditory information processing in cortical level and in function of time. $^{6}$

The waves positive $1(\mathrm{P} 1)$, negative $1(\mathrm{~N} 1)$, positive $2(\mathrm{P} 2)$, negative 2 (N2), and positive 3 (P3) are part of the auditory evoked long latency potentials. They are subdivided into exogenous sensory evoked potentials (P1, N1, P2, N2), which are influenced by the physical characteristics of the stimulus, such as intensity, duration, and frequency, and endogenous sensory evoked potential (P3), predominantly influenced by events related to cognitive skills. ${ }^{7}$

In adults, it is possible to evaluate exogenous and endogenous potentials. The criteria of normality in relation to cognitive skills are verified from the latency of these components. Normality criteria are described in the literature. ${ }^{8}$ Thus, significant increases in latency indicate functional or anatomical alteration of these potential generating sites, reflecting cognitive abilities.

However, care must be taken in interpreting these results, because these potentials cannot be used alone to diagnose central nervous system diseases. The behavioral assessment of auditory processing and even imaging are essential for interpreting the findings.

In babies, is possible to evaluate exogenous potentials (P1, $\mathrm{N} 1, \mathrm{P} 2$, and N2) because these potentials represent the cortical ability of detecting acoustic stimulus and do not depend on the individual's attention.

Regarding the exogenous components, some authors believe that the component P1 originates from the Heschl gyrus or from the area of secondary auditory; the component N1 originates from the frontal lobe, although the generating areas of that component are not clear; the component P2 originates from the anterior superior temporal gyrus; and the component N2 arises next to the supratemporal regions, including the frontal cortex. ${ }^{2}$

From that and from the necessity of knowing the characteristics of auditory evoked long latency potentials in neonates, this study aimed at researching the exogenous potential in term and preterm born infants during their first month of life, as well as comparing the latency among the groups.

\section{Methods}

This research is part of a project called "Metabolismo oxidativo e maturação das vias auditivas em prematuros," registered in the ethics committee from Universidade Federal de Santa Maria, Santa Maria, RS, Brazil, no. 05704712.8.0000.5346. This is a transversal, prospective, contemporary, and comparative study.

The evaluations of the research were performed at the hearing electrophysiology sector at Hospital Universitário de Santa Maria (HUSM). Only babies participated in this study. Their parents or representatives, after receiving information about the purposes and methodology of the research, agreed with the procedures to be performed and signed the informed consent form.

The sample consisted of 25 newborns, 15 term (control group) and 10 preterm (study group) infants, male and female, who had the newborn hearing screening (NHS) at HUSM during their first month of life. The infants were considered as premature when the gestational age was less than 37 weeks, according to the classification by the World Health Organization (1974). ${ }^{9}$

The inclusion criteria were the following:

- Term-born infants (control group) of 37 weeks' gestational age or more, without risk factors for hearing loss, with transient-evoked otoacoustic emissions (TEOAE) in both ears and eyelid closure-enhanced reflex in the NHS

- Preterm-born infants (study group) of 37 weeks' gestational age or less, with and without risk factors for hearing loss, with TEOAE in both ears in the NHS, with or without eyelid closure-enhanced reflex

The TEOAEs were researched in both ears with nonlinear stimulation and a window of 20 milliseconds, with frequencies of $1,000,1,500,2,000,3,000$, and $4,000 \mathrm{~Hz}$ and with approximated intensity of $80 \mathrm{~dB}$ SPL (decibel sound pressure level). The TEOAEs were considered when the signal-to-noise ratio was greater or equal to $3 \mathrm{~dB}$ for the frequency of $1,000 \mathrm{~Hz}$, and $6 \mathrm{~dB}$ for the other frequencies, in at least three of the five researched frequencies. The TEOAE registration happened in silence, with the equipment Intelligent Hearing Systems (IHS), SmartTrOAE system (IHS Miami, USA).

The eyelid closure-enhanced reflex was researched through an instrument called "multiple bells," with $\sim 90 \mathrm{~dB}$ SPL of intensity. It must be reinforced that the TEOAE research had the purpose of excluding newborns with cochlear hearing loss. The acoustic impedance measurements were also performed to exclude newborn with changes conductive. ${ }^{10}$ Auditory evoked long latency potentials research used the IHS equipment, Smart EP system, with two channels.

For electrophysiologic evaluation, the infants remained in natural sleep in the lap of the representative. It was not possible to evaluate the infants while they were awake, because their movement altered the electrical stability of the examination and the trustworthiness of the responses.

After cleaning the children's skin with abrasive paste and alcohol, electrodes were introduced to the skin with conductive electrolytic paste and plaster, with the active electrode in the front $(\mathrm{Fz})$, the ground $(\mathrm{Fpz})$ in the front, and the reference placed on the left mastoid (M1) and right mastoid (M2). The individual impedance of the electrodes was $1(\mathrm{k} \Omega)$ for all the evaluations. 
The auditory evoked long latency potentials were researched binaurally, through insertion phones, with frequent/ba/ and rare /ga/ speech stimulation, with rarefaction click polarity, trapezoi-

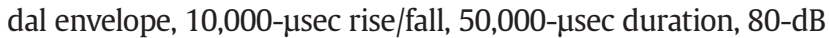
HL intensity. The frequent stimulations were 80\% ( 120 stimuli) of the presentation and the rare stimulations were $20 \%(\sim 30$ stimuli). The stimuli were presented randomly. The presentation rate was one stimulus per second, into the range recommended by McPherson et $\mathrm{al}^{11}{ }^{11}$ and the interval among the stimuli was 1 second, according to Polich. ${ }^{12}$ To make the examinations reliable, traces were replicated.

In evaluation of the auditory evoked long latency potentials, factors considered were presence or absence of the components P1, N1, P2, and N2 in the traces, which correspond to the frequent stimulations (syllable /ba/) as well as their latencies.

The data were organized in worksheets, in the program Microsoft Excel (IHS, Miami, USA), and they were analyzed statistically through the program Statistical Package for Social Sciences. (IBM, USA), version 17.0 for Windows. The Student $t$ test was used to compare the averages in paired samples, and to compare independent samples, the Wilcoxon and Mann-Whitney tests were used. The results were considered as significant when $p<0.05$, with confidence interval of $95 \%$.

\section{Results}

The average gestational age for the group of term infants was 38 weeks $( \pm 1.3$ ), and the same average for the group of premature infants was 33 weeks $( \pm 1.6)$. The age average in the evaluation moment was 9.9 days for the term group and 9.1 days for the premature group. The difference between the gestational age and the corrected age between the groups was statistically significant. The descriptive analyses related to the ages are described in -Table $\mathbf{1}$.

In our study, it was possible to observe a high peak of $\sim 230$ milliseconds for the control group and peak of $\sim 201$ milliseconds for the study group, and high deflection of $\sim 341$ milliseconds for the control group and 302 milliseconds for the study group. They were called P1 and N1, respectively. The component P2 was observed in only one term infant (peak of $\sim 270$ milliseconds) and in two premature infants (peak of 290 milliseconds). They were not statistically analyzed.

There was no statistically significant difference in latencies of the components P1 and N1, for the right ear and for the left ear, between the studied groups. There was also no statistically significant difference between the term and premature born infants in the latencies of the components P1 and N1.

The intra- and intergroup results are described in -Table 2.

\section{Discussion}

The research about auditory evoked long latency potentials in newborns is a recent and controversial subject, because of the maturation of the cortical structures. However, some studies have already noted that those potentials may be evidenced during childhood, ${ }^{2-4,13-16}$ as most synaptic modifications occur in the first years of life. Thus, the cortical auditory potentials may be useful to predict possible cognitive and language disorders.

This study showed the exogenous components of the cortical auditory potentials in newborns, agreeing with other studies. ${ }^{2,3,13-15}$ The exogenous components are cortical responses for the detection of the acoustic stimulation, so do not depend on attention skills. For this reason, it can be used in neonates.

Our study observed a high peak ( $\sim 20$ milliseconds) for the control group and peak of $\sim 201$ milliseconds for the study group, and there was high deflection, around 341 milliseconds for the control group and 302 milliseconds for the study group. The peak and the deflection are named P1 and N1, respectively, because we believe that the positive peak and the deflection may correspond to those potentials, therefore, with increased latencies, because of immaturity of cortical structures.

The existence of high peak and high deflection in traces of newborns no more than 1 month old agrees with other studies. ${ }^{2,13,15}$ However, those authors called the components P2 and N2, different from the denomination used in this research (P1 and N1), possibly because of the latencies of the potentials. In those studies, the high peak was around 300 milliseconds and the deflection was around 600 milliseconds. The P2 and N2 components have the highest latencies. Another author also mentioned the denomination of the infants' potentials, observing that it is variable in literature. ${ }^{2}$ Other research also used the latency of the potentials, naming them P100, N250, and P450, which does not correspond to the nomenclature used for adults. ${ }^{15}$

In this study, there was no statistically significant difference between the latencies of the components P1 and N1

Table 1 Descriptive measurements for gestational age and corrected age, according to the group

\begin{tabular}{|c|c|c|c|c|c|c|c|}
\hline \multirow[t]{3}{*}{ Age (d) } & \multicolumn{6}{|c|}{ Groups } & \multirow[t]{3}{*}{$p^{a}$} \\
\hline & \multicolumn{3}{|c|}{ Term $(n=15)$} & \multicolumn{3}{|c|}{ Premature $(n=10)$} & \\
\hline & Average & Standard deviation & Median & Average & Standard deviation & Median & \\
\hline Gestational & 38.9 & 1.3 & 39.0 & 33.9 & 1.6 & 34.0 & $<0.001^{\mathrm{a}}$ \\
\hline Corrected & 9.9 & 11.3 & 2.0 & 15.7 & 9.1 & 18.0 & $0.186^{b}$ \\
\hline
\end{tabular}

${ }^{\text {a }}$ Student $t$ test for the independent groups.

${ }^{\mathrm{b}}$ Mann-Whitney test. 
Table 2 Comparison of the latencies by the components P1 and N1 for the right ear and for the left ear, according to the groups

\begin{tabular}{|c|c|c|c|c|c|c|c|}
\hline \multirow[t]{3}{*}{ Age (d) } & \multicolumn{6}{|c|}{ Groups } & \multirow[t]{3}{*}{$p^{a}$} \\
\hline & \multicolumn{3}{|c|}{ Term $(n=15)$} & \multicolumn{3}{|c|}{ Premature $(n=10)$} & \\
\hline & Average & Standard deviation & Median & Average & Standard deviation & Median & \\
\hline \multicolumn{8}{|c|}{ Latency P1 wave } \\
\hline Left ear & 230.4 & 58.8 & 254.0 & 201.8 & 72.7 & 209.0 & $0.289^{\mathrm{a}}$ \\
\hline Right ear & 229.3 & 57.7 & 262.0 & 205.0 & 73.8 & 210.0 & $0.365^{\mathrm{a}}$ \\
\hline$p^{c}$ & \multicolumn{3}{|l|}{0.807} & \multicolumn{3}{|l|}{0.220} & \\
\hline \multicolumn{8}{|c|}{ Latency N1 wave } \\
\hline Left ear & 341.2 & 84.1 & 386.0 & 302.8 & 102.7 & 355.0 & $0.335^{\mathrm{b}}$ \\
\hline Right ear & 336.6 & 85.7 & 386.0 & 298.2 & 101.8 & 349.0 & $0.337^{b}$ \\
\hline$p^{\mathrm{d}}$ & \multicolumn{3}{|l|}{0.398} & \multicolumn{3}{|l|}{0.454} & \\
\hline
\end{tabular}

${ }^{a}$ Student $t$ test for the independent groups.

${ }^{\mathrm{b}}$ Mann-Whitney test.

'Student $t$ test for paired data.

dWilcoxon test.

between the groups of term and preterm infants. Those results are different from the results found by other authors. ${ }^{13}$ According to those authors, the peak $\sim 200$ milliseconds (P1) presented statistically significant difference between the groups. However, the results found in our study agree with other research, ${ }^{3}$ in which the latency of the P1 components was similar in the group of term and preterm infants. The same authors warn that prematurity associated with absence of cortical potentials may be a risk factor for further cognitive alterations.

The optimum state of the infants during the examination is still debated in literature, because some studies evaluated neonates when they were sleeping, others evaluated awake children, and some studies did it in both ways. Nevertheless, authors noted no differences in the traces of the cortical potentials for both ways of evaluation. ${ }^{2}$

Active sleep is part of REM sleep, and it is defined as a state of newborns with closed eyes, with irregular breathing, and without strong movements. This sleep state may be identified by observing infants' behavior. ${ }^{17}$ Other research mentioned that the evoked auditory potentials may be obtained with newborns during active sleep, ${ }^{18}$ when the morphology of the waves is similar to the vigil state, which makes the examination useful, without the necessity of responses by the children. Some authors also noted that there are no differences in the encephalogram of newborns during active sleep and during alert state. ${ }^{19}$ For this reason, the auditory evoked long latency potentials may be evaluated when the baby is sleeping, which makes the examination useful.

In this study, it was possible to obtain results with newborns in natural sleep, as other studies have done. ${ }^{14,15,18}$ It is highlighted that in those studies the evaluation in natural sleep was performed only with neonates of no more than 1 month of age. The other babies were evaluated while in vigil state.

Application of cortical potentials in babies is recent and controversial, mainly because of the maturation of the cortical structures and because of the state of the neonates during the evaluation. In addition, the denomination of the potentials in infants is diverse in the literature. Thus, more research is necessary to make this examination useful to predict possible cortical alteration in newborns and, as a consequence, to become an evaluation of precocious detection of cognitive and language disorders.

\section{Conclusion}

It was possible to observe the exogenous components $\mathrm{P} 1$ and N1 of the cortical auditory potentials in newborns of no more than 1 month of age, in term and in preterm infants.

The research about auditory evoked long latency potentials in newborns is recent. More studies in this area are necessary to understand the characteristics of those potentials in newborns and young children and to use those potentials in the future to predict cognitive and linguistic disorders.

\section{References}

1 Cóser MJS, Cóser PL, Pedroso FS, Rigon R, Cioqueta E. P300 auditory evoked potential latency in elderly. Braz J Otorhinolaryngol 2010; 76(3):287-293

2 Kushnerenko EV. Maturation of the cortical auditory event related brain potentials in infancy [dissertation]. Helsinki, Finland: University of Helsinki, Department of Psychology; 2003

3 Fellman V, Kushnerenko E, Mikkola K, Ceponiene R, Leipala J, Naatanen R. Atypical auditory event-related potentials in preterm infants during the first year of life: a possible sign of cognitive dysfunction? Pediatr Res 2004;56(2):291-297

4 Choudhury N, Benasich AA. Maturation of auditory evoked potentials from 6 to 48 months: prediction to 3 and 4 year language and cognitive abilities. Clin Neurophysiol 2011;122(2):320-338

5 Molfese DL, Molfese VJ. Discrimination of language skills at five years-of-age using event-related potentials recorded at birth. Dev Neuropsychol 1997;13(2):135-156

6 Reis ACMBR, Frizzo ACF. Potencial Evocado Auditivo de Longa Latência. In: Bevilacqua MC, Martinez MAN, Balen AS, Pupu AC, Reis ACMB, Frota S, eds. Tratado de Audiologia. São Paulo, Brasil: Santos; 2011:231-260 
7 Duarte JL, Alvarenga KF, Banhara MR, et al. P300-long-latency auditory evoked potential in normal hearing subjects: simultaneous recording value in Fz and Cz. Braz J Otorhinolaryngol 2009; 75(2):231-236

8 Kraus N, Mcgee T. Potenciais auditivos evocaados de longa latência. In: Katz J, ed. Tratado de Audiologia Clínica. 4ª ed. São Paulo, Brasil: Manoele; 2002:403-420

9 World Health Organization Scientist Group on Health Statistics Methodology Related to Perinatal Events. Who, Genebra, 1974, p. 32. In: Costa SMB, Costa Filho AO, eds. O estudo dos potenciais evocados acusticamente de tronco cerebral em recém-nascidos pré-termo. Braz J Otorhinolaryngol 1998;64(3):231-238

10 Jerger J. Clinical experience with impedance audiometry. Arch Otolaryngol 1970;92(4):311-324

11 McPherson DL, Ballachanda BB, Kaf W. Middle and long latency evoked potential. In: Roeser RJ, Valente M, Dunn HH, eds. Audiology: Diagnosis. New York, NY: Thieme; 2008:443-477

12 Polich J. P300 in clinical applications: meaning, method and measurement. Am J EEG Technol 1991;31:201-231

13 Pasman JW, Rotteveel JJ, de Graaf R, Stegeman DF, Visco YM. The effect of preterm birth on brainstem, middle latency and cortical auditory evoked responses (BMC AERs). Early Hum Dev 1992; 31(2):113-129

14 Kushnerenko E, Ceponiene R, Balan P, Fellman V, Huotilaine M, Näätäne R. Maturation of the auditory event-related potentials during the first year of life. Neuroreport 2002;13(1):47-51

15 Wunderlich JL, Cone-Wesson BK, Shepherd R. Maturation of the cortical auditory evoked potential in infants and young children. Hear Res 2006;212(1-2):185-202

16 Ceponiene R, Shestakova A, Balan P, Alku P, Yiaguchi K, Näätänen R. Children's auditory event-related potentials index sound complexity and “speechness.". Int J Neurosci 2001;109(3-4): 245-260

17 Khan RL, Raya JP, Nunes ML. Avaliação do estado comportamental durante o sono em recém-nascidos. J Epilepsy Clin Neurophysiol 2009;15(1):25-29

18 Cheour M, Leppänen PH, Kraus N. Mismatch negativity (MMN) as a tool for investigating auditory discrimination and sensory memory in infants and children. Clin Neurophysiol 2000; 111(1):4-16

19 De Weerd AW. Atlas of EEG in the First Months of Life. Amsterdam, the Netherlands: Elsevier; 1995 